\title{
Temporal Model of the Drivers of Household PV Purchase in Australia
}

\author{
Glen Currie $^{1}$ (D) $\cdot$ Robin Evans $^{1} \cdot$ Colin Duffield $^{1} \cdot$ Iven Mareels $^{1,2}$
}

Received: 28 March 2019 / Accepted: 2 September 2019 / Published online: 14 September 2019

(C) Springer Nature Singapore Pte Ltd. 2019

\begin{abstract}
Australian household PV adoption rates are the highest in the world and this is causing a rise in technical problems and the cost of the distribution system. This paper offers a predictive model of household PV purchases in Australia and this could be used in policy to better manage PV uptake patterns.

The analysis used 1.6 million domestic PV installation decisions over 11 years from 2006 to 2017 and is statistically significant. Autoregressive integrated moving average (ARIMA) modelling was used to reduce non-stationarity in the data and Granger Causal modelling showed the most effective policy levers are price, subsidy, business confidence and PV feed-in tariffs.

This analysis develops a model of Australian PV adoption and increases understanding of consumer roles in the future electricity system. This is compared to other similar models in the literature. The key contribution is that the scale of the model creates a temporal prediction that is not in other literature. The second contribution is that the model may apply to other household energy decisions. This was measured by comparing Australian PV adoption to solar hot water adoption.
\end{abstract}

Keywords Australia $\cdot$ Granger causal $\cdot$ Household $\cdot$ Photovoltaics $\cdot$ PV

\section{Motivation}

This paper looks to increase understanding of the drivers of household PV adoption. The aim is to offer a tool for business and government using detailed research on household PV adoption including a temporal forecasting model.

The emerging role of customers in the Australian grid has appeared over the past decade with huge penetrations of PV, air-conditioning and pool pumps. If we do not reform the energy system, this disruption at the customer end of the electricity system will continue to push up the cost of electricity.

In areas of Australia, PV is on 50\% of building stock. Australia also has strong solar insolation, so the PV produces high electricity flows. Therefore, PV grid issues are acutely felt. This is exacerbated in areas with long feeders with significant voltage droop [13]. PV can lift feeder voltages and cause a backwards flow of power at the transformer.

Glen Currie

glen.currie@unimelb.edu.au

1 School of Engineering, The University of Melbourne, Melbourne, Australia

2 Lab Director, IBM Research Australia, Melbourne, Australia
Protection from this is needed as the grid is designed for single direction flow for safety reasons. PV systems also cut out when voltages rise above the set voltage limit [5].

Reform of the electricity system is urgent and critical and may include government policy to manage PV adoption rates. Regulatory change is starting. The Australian Energy Market Commission "Power of Choice" review in 2012 was the first major Australian Government report to recognise the role of customers in energy planning. It covered peak shifting, efficiency, and customers generating their own electricity. There is an increasing focus on customer actions in the AEMO press releases in 2017-18 and the Australian Government energy strategy by the Chief Scientist Alan Finkel [16].

\section{Contributions}

The key contribution is that the scale of the model creates a temporal prediction more suitable for policy than other models in the literature. Our research offers a temporal model of PV uptake and could be used for grid planning and energy policy. Our model explains two thirds of the "Granger Causal" driver of PV purchase decisions using time lagged measures of business conditions, earlier PV purchases, the PV feed-in tariff, 
electricity prices and the price of PV. This model was statistically significant and used data on the 1.6 million PV household installations in Australia between 2006 and 2017. This included testing of 36 variables.

The second contribution is that the model may apply to other household energy decisions. This was assessed using a comparison with solar hot water household adoption in Australia. The model may be effectively applied to the uptake of other products such as batteries.

\section{Literature Review}

Boulaire et al. [10] modelled Australian PV uptake using similar techniques to our research. We undertook further modelling using ARIMA and Granger Causal techniques to facilitate forecasting.

Agent-based modelling (ABM) is popular in the analysis of consumer uptake and can call on a number of theories to look at PV uptake [25]. ABM is limited to modelled households and is not an effective way to predict district energy patterns, which are a key input to understanding the effect of policy. Our research is district based and does not use ABM.

Australian research by Sommerfeld et al. [29] offers an excellent window into socio-economic dynamics in household PV uptake and is a nuanced input to future policies and incentives. Our model can be generalised more easily than the socio-economic model of Sommerfeld, Buys et al. Evidence of this generalisability of our model is that it maintained high statistical accuracy in all 32 different areas of Australia. One of the interesting conclusions of our research was that there was a negative relationship between income and PV adoption. This was also the conclusion of Bashiri and Alizadeh [9] in analysis using binary logistic regression on a population in Tehran, Iran.
The use of socio-economic modelling is an important input to policy, and the work by Candas et al. [11] is one of the most potent in forecasting policy impacts on PV uptake. They look at the economics of PV for a house in Europe. Our model is socio-technical and could more easily fit into policy that aims for optimisation of the electricity system. This is because the energy system is so technically and socially complex. Our socio-technical model is therefore more suited to driving long-term, lower-cost outcomes than socio-economic modelling.

GIS-ABM [23, 28] can be used for an accurate PV adoption model. GIS-ABM relies on GIS understanding of the specific built environment which limits use for national policy. Over time, as GIS-ABM becomes more ubiquitous, this technique may be a powerful next step in understanding PV diffusion and the diffusion of other energy technologies. Limits exist to the use of GIS-ABM indesigning policy, due to the lack of comprehensive GIS and ABM information. The advantage that our model offers is the ability to use broad datasets on the national scale to formulate policy.

\section{Research Design}

Nearly two-million Australian homes have installed PV and been subsidised by the Australian Government, therefore supplying detailed data for the installation month and postcode for each PV installation. Table 1 shows the number of PV installations by state and by year.

This paper models Australian PV adoption data. This included spatial modelling and ARIMA analysis of the 1.6 million domestic PV installation decisions over 11 years from 2006 to 2017. This is from a dataset showing monthly rates per postcode and there are 8900 people in the average Australian postcode. Social measures for Australian postcodes are available from the Australian Government Census (run
Table 1 The number of domestic $\mathrm{PV}$ installation by state/territory

\begin{tabular}{llllllllll}
\hline Year & QLD & NSW & VIC & WA & SA & TAS & ACT & NT & National \\
\hline $2001-7$ & 475 & 779 & 828 & 262 & 1037 & 26 & 102 & 26 & 3535 \\
2008 & 3087 & 2890 & 2036 & 2068 & 3456 & 161 & 278 & 88 & 14,064 \\
2009 & 18,283 & 14,008 & 11,847 & 11,157 & 8569 & 1452 & 803 & 215 & 66,334 \\
2010 & 48,697 & 69,988 & 35,676 & 22,293 & 16,705 & 1889 & 2323 & 637 & 198,208 \\
2011 & 95,303 & 80,272 & 60,214 & 51,667 & 63,553 & 2475 & 6860 & 401 & 360,745 \\
2012 & 130,252 & 53,961 & 66,204 & 42,653 & 41,851 & 6364 & 1522 & 513 & 343,320 \\
2013 & 71,197 & 33,998 & 33,332 & 21,600 & 29,187 & 7658 & 2411 & 1024 & 200,407 \\
2014 & 57,748 & 37,210 & 40,061 & 23,496 & 15,166 & 4207 & 1225 & 1026 & 180,139 \\
2015 & 39,510 & 33,484 & 31,360 & 20,799 & 12,084 & 2020 & 1066 & 1197 & 141,520 \\
2016 & 35,717 & 29,796 & 26,506 & 25,302 & 12,682 & 2580 & 999 & 1793 & 135,374 \\
TOTAL & 501,387 & 357,438 & 308,977 & 221,533 & 205,946 & 28,882 & 17,619 & 7024 & $1,648,805$ \\
\hline
\end{tabular}


every five years). We also used a measure of business confidence from one of the major banks (National Australia Bank).

\section{Spatial Analysis Method}

Our spatial analysis of Australian PV uptake used 35 variables that included socio-economic, business confidence, energy use, and voting data for each of the 2300 postcodes in Australia. We considered carbon certificates, and PV feed-in tariffs. The PV adoption rates were sourced from the APVI [6]. The key steps of this method are:

- Check and clean the dataset (some postcodes crossed into two States);

- Map the dataset to look for patterns and understand the data using ARCMAP from ESRI [15] (ESRI, 2016);

- Build 35 socio-economic measures by postcode;

- Test for correlation to rates of PV uptake using SPSS Statistics 22 (2015);

a. Check for linear relationships;

b. Plot each variable to check for multivariate normality

c. Seek to minimise adjusted $\mathrm{R}^{2}$ and standard error of estimated model;

d. Durbin-Watson test for linear autocorrelation aim between 1.5 and 2.5;

e. Check collinearity using tolerance 0.1 and Variance Inflation Factor (VIF) over 10 for all variables;

\section{f. F test}

- Test with spatial regression; and

- Test with temporal spatial regression.

There has been a gradual increase in PV system size. This introduces a skew in the total volume of PV, but the focus of this research is on adoption (not on the size of system). Another important variable used in the testing was the electricity price and consumption in Australia. The pattern for electricity use density in Melbourne shows in Fig. 1

From 2003 to 2006, the average household cost of electricity was quite flat but since 2006, it has risen sharply. The Australian Bureau of Statistics (ABS) has ran a national survey of electricity use, but not included the Northern Territory (NT), so our NT data is from ABS benchmarks [1] and an ACIL calculation [2]. Federal election data was drawn from the Australian Electoral Commission [8].

Owning a separate house and the previous purchase of a solar hot-water system were the strongest predictors, which explained about $2 / 3$ of the purchase motivation in urban areas [12]. There were different results found in the rural take-up patterns. This was also found in a similar study in NSW [20].
Figure 2 shows the interplay with PV price, subsidy, and feed-in tariffs.

\section{Temporal Analysis Method}

Using the results from the above spatial analysis, to name important variables, the dataset was analysed from a time-series perspective using ARIMA modelling. This temporal model studies all Australian PV installations from 2006 to 2017. Our spatial study has previously shown the different patterns between urban and rural PV purchase drivers. Therefore we used an Australian Government remoteness categorisation [24] which splits the states into up to 5 levels of remoteness and split Australia into 32 regions. Adil and Ko [3] suggest urban planning could use such a model of the energy system and changes in local energy infrastructure to accommodate domestic energy systems. They argue that urban planning has missed the dynamic system effects of these decentralized energy systems. Our temporal modelling developed a forecasting model of domestic PV adoption in Australia.

Temporal variables added at this stage include electricity use and pricing by each of the 32 areas from a finer resolution from Australian Bureau of Statistics 2010-2012 survey of households. This electricity use and pricing data was then spread over the eleven-year period. We also added feed-in tariff at time of installation (at the state level) and the price of PV installs by state by year were converted to monthly figures after taking a straight-line average.

Analysis of PV grid issues has included spatial modelling, ARIMA modelling and survey. The software used included ARCMAP [15] and IBM SPSS Statistics 22 [22], and IBM SPSS Modeler 18.1 [22]. ARIMA modelling was in SPSS Model 18.1, as its graphical imagery was particularly useful in showing a flow for the modelling. The graphical representation showed input files to the left, the regression techniques as icons, and the output files as separate icons. Iterative modelling was possible due to the easy visualisation and interfaces in this software. The method follows:

- Test with ARIMA;

1. Create temporal dataset in monthly intervals for 32 regions of Australia;

2. Monthly measures for census data created using a straight-line average for each of the 32 regions of Australia using ARCMAP and SPSS Statistics;

3. ARIMA modelling used SPSS Model 18.1 and then verified in SPSS Statistics 22; 


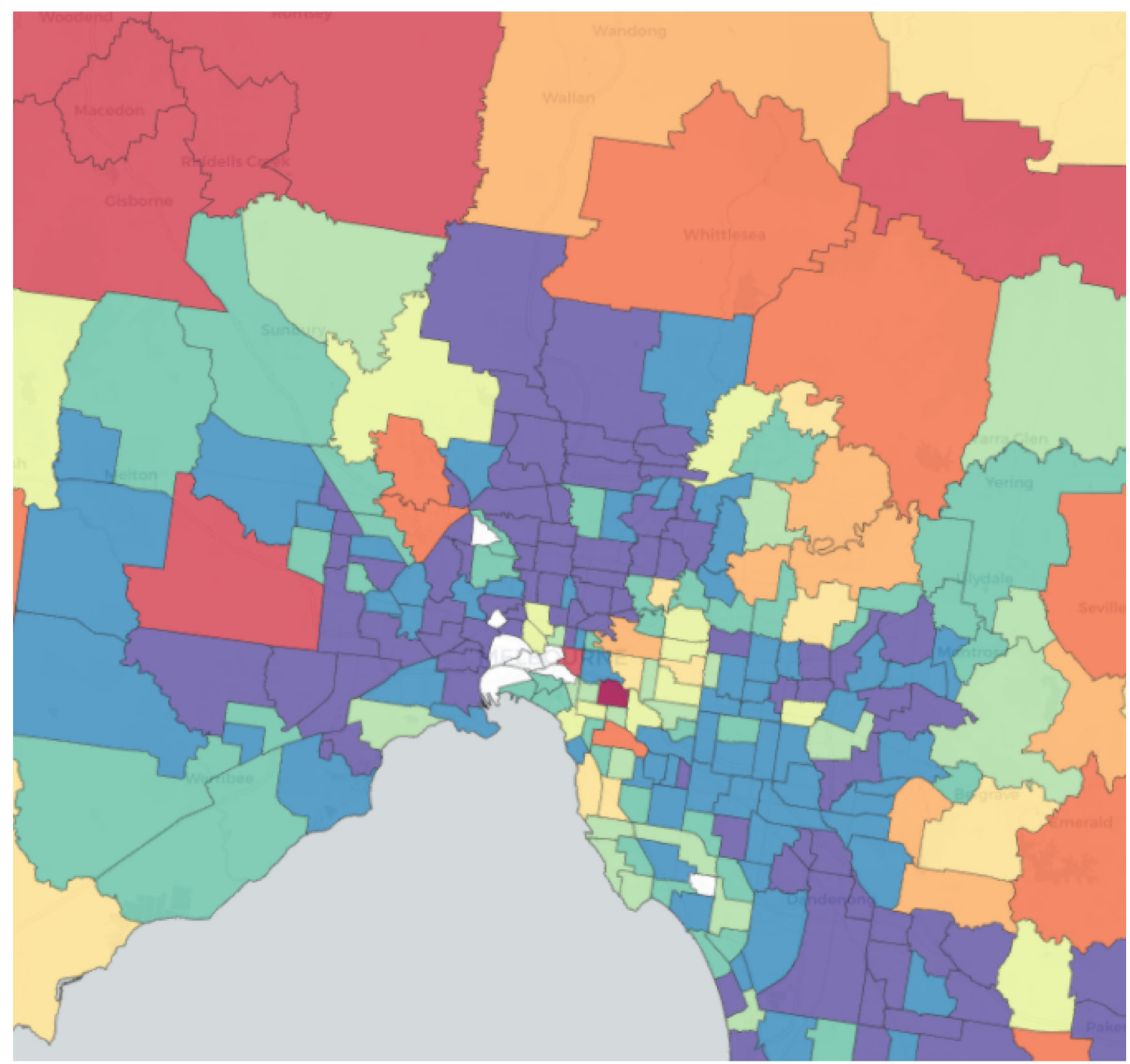

\section{Legends}

\section{Consumed energy by SA2}

Mean - $2012(\mathrm{kWh})$

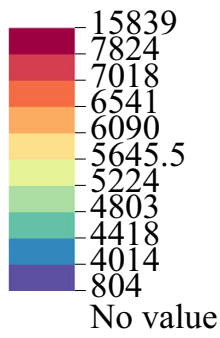

Fig. 1 Electricity use averages for Melbourne [7]

- Position the predictive model in policy options using a survey and test views of distribution companies, inverter regulation, export limits, pricing, and storage.
Importantly, Granger [18] has been widely criticised. Toda and Yamamoto [31] have offered improvements to the Granger Causal tool, and Stern [30] also offers useful insights on Granger Causal in research on energy and economic 
Fig. 2 Australian household PV installations, price, subsidy, and feed-in tariff

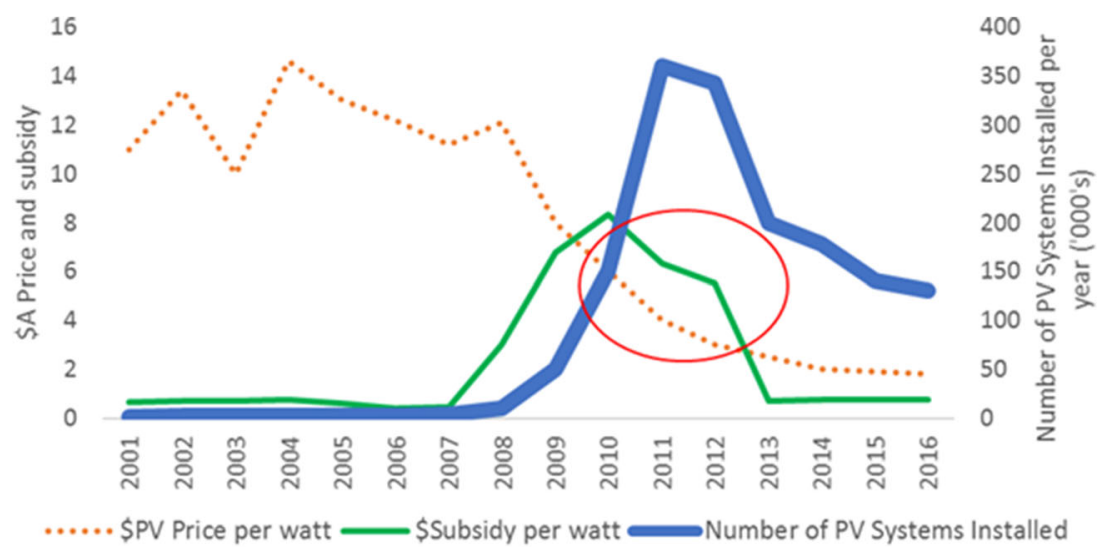

growth in Sweden over 150 years. Eichler [14] notes that "Granger's definition covers only direct causal relationships" and the modelling in this research used variables that were directly causal, so the Granger Causal model can be used here with some confidence.

\section{Results}

Spatial modelling showed a correlation between postcodes that had high PV uptake with postcodes with high solar hot water uptake as shown in Table 2.

Spatial modelling helped us choose the more important drivers of solar uptake and the mapping showed the fringe of cities had the highest concentrations of PV uptake. This led to our strategy for the ARIMA modelling of using the Australian Government remoteness categorisation [24] which splits the states into up to 5 levels of remoteness, splitting Australia into 32 regions.

Akaike's seminal work [4] on the statistical inferencing has wide acceptance for time series modelling and has led to a range of similar tests. AIC and $\mathrm{BIC}$ are useful to compare different things to be modelled, so for example, each of the geographic areas have a separate, comparable AIC. Lower AIC and BIC shows a better model (even when the number is negative). AIC was used to assess a range of variables, including assessing the effect of different variables on any

Table 2 Testing the correlation between PV and solar-hot-water in Australia

PV and solar-hot-water correlation

\begin{tabular}{llll}
\hline & PV & $\begin{array}{l}\text { \%solar-hot- } \\
\text { water }\end{array}$ \\
\hline \% homes with PV & Pearson Correlation & 1 & .571 \\
& Sig. (2-tailed) & & .000 \\
& $\mathrm{~N}$ & 1098 & 1098 \\
\hline
\end{tabular}

geographic areas that had shown poor results in the first stage of modelling. Pearson's coefficient was also a useful measure in model choice.

The software SPSS Modeller 18.1 was used for ARIMA modelling. Dozens of models were assessed, and six variables then chosen for comparison with PV uptake. They are variables for business confidence, carbon subsidy, PV feed-in tariffs, PV system price, electricity use and electricity prices.

Some higher performing models include:

- One with 5 variables (carbon subsidy, PV feed-in tariffs, PV system price, electricity use and electricity prices) gave a Pearson Correlation over 0.95 in 30 areas (but not in two remote areas).

- Another model with 5 variables (business confidence, carbon subsidy, PV feed-in tariffs, electricity use and electricity price) generated a Pearson Correlation of over 0.95 in all areas except in two remote areas.

- Another model with four variables (business confidence, PV feed-in tariffs, carbon subsidy and electricity prices) generated a Pearson Correlation over 0.87 for all urban areas but gave low scores for all rural areas.

The next step was to look for patterns in the above models which showed Lag 1 had significant carbon subsidy influence, Lag 2 had significant electricity price influence, Lag 3 had significant feed-in tariff and average electricity use influence and Lag 4 had significant carbon subsidy and price of PV system influence. This next step used tabulation of all results and a manual analysis.

\section{Outcome of ARIMA Modelling}

A large number of models were tested and the final selected model explained about $2 / 3$ of the cause of the PV purchase [18]. The predictive power was only strong for up to 6 months and Fig. 3 illustrates the correlation for the inner city of Sydney. The model is: 
Fig. 3 Sample of the correlation between actual PV installations and the model output
Sydney City Area 10

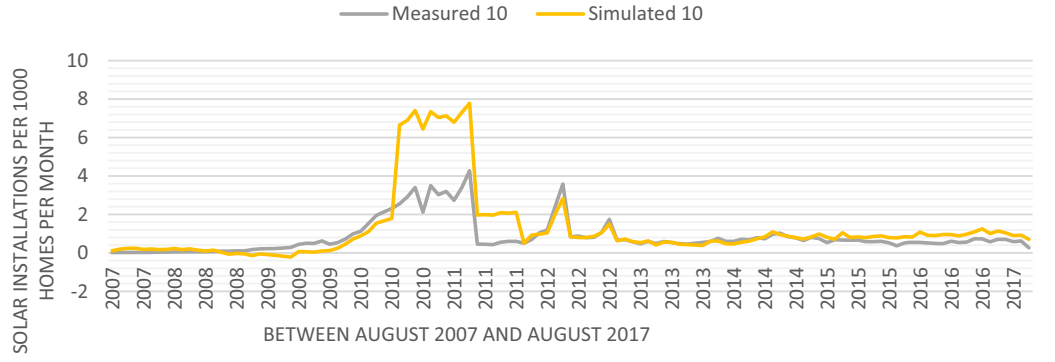

- 1-month lag autocorrelation, weighting 0.4;

- 4-month lag on PV price in \$A (inclusive of subsidy), negative weighting 0.01 ;

- 8-month lag on business confidence index, weighting 0.02 ;

- 8-month lag on feed-in tariff in \$A cents, weighting 0.05;

- 12-month lag autocorrelation, weighting 0.3 .

\section{Discussion and Policy Implications}

Distribution companies have the option of installing expensive equipment to manage PV overvoltage but this expense drives up the cost of electricity [5]. Policy to address PV overvoltage could include incentives from distribution companies, inverter regulation, export limits, pricing signals, and storage.

Inverter regulation can include autonomously checking voltage and setting output voltage [26]. Other options include redirection of PV output to storage and PV export limits.

The Australian Government has a large policy arm trying to include the customer in the energy policy mix, but they are struggling to deliver adequate and prompt energy policy. Federal politics demands that big ticket items such as the sale of Liddle Coal Power Plant[21, 27] are the headline grabbers preferred by politicians. In addition, there is a political fear of dabbling with the customer end of the grid and the Federal Government prefers to task the State Governments with the job of managing the customer end of the grid (states have energy ombudsmen and manage hardship cases). Finally, a potent barrier to change is that all Federal energy law must be agreed by all the states before being passed by the South Australian parliament.

To optimise the electricity distribution system, there will need to be an element of government regulation and an active private industry driven by cost reflective price signals. The innovations will need to innovative and be sophisticated for loads such as electric vehicles [32]. There may be new markets for load reduction, voltage and frequency and other grid services.

If PV inverters moderate their imposition on the line with voltage set points close to the current grid voltage this will help reduce the cutting out of PV inverters. Inverters with this type of control are known as autonomous controllers, and they learn optimal set-points for each inverter [17]. Tests on Virtual Power Plants (VPP's) are underway in Victoria in a project between the distribution company United Energy and the aggregator GreenSync [19].

Technology solutions tend to be expensive and a lower cost method is to get agreement on standards and regulation. This includes the need for new inverter technology that offers services such as sinusoidal power shaping, but the key issue is to ensure inverters are programmable to allow future upgrades.

Where they exist, the PV export limits in Australia are usually $4.8 \mathrm{kw}$. Instead of using a blunt instrument like a PV export limit, we could dynamically control inverters and reduce the need for PV export limits. The most potent tool being the addition of storage batteries. Distribution companies can use other technical options to allow reverse power flow, but in high PV areas, storage is the only solution for high ramp rates (when shading comes on and off). Community energy and peer-to-peer system may also help with improving the system constraint.

\section{Conclusion}

An electricity system with a large amount of household PV is more difficult to manage, but this is not the only source of grid instability. There is also grid instability coming from heavy loads such as air-conditioning and the increased instability from large renewable generators.

Improved grid stability could come from better control of PV uptake using the ARIMA model presented in this paper which explains two thirds of the "Granger Causal" driver of PV purchase decisions. The model 
could also be applied to other customer actions such as storage purchase. There are many further policy options [13].

Acknowledgements This research received grants from the University of Melbourne and through the class of 1948 scholarship Sir Louis Matheson Prize, 2018.

\section{Compliance with ethical standards}

Conflict of interest None.

Abbreviations ARCMAP, ESRI spatial GIS and statistical software; ARIMA, Autoregressive integrated moving average statistical technique; AIC, Akaike Index used in statistics to compare models; BIC, Bayesian Index used in statistics to compare models; PV, Photovoltaic systems; PV feed-in tariff, Subsidy paid for electricity that is generated by PV systems; SPSS, IBM software for statistics; SPSS Modeler, IBM software for statistical models

\section{References}

1. ABS. (2011). 4602.0.55.001-environmental issues: energy use and conservation tables, mar 2011. Canberra: Australian Government Retrieved from http://www.abs.gov.au/AUSSTATS/abs@.nsf/ DetailsPage/4602.0.55.001Mar\%202011?OpenDocument

2. ACIL. (2015). Electricity Benchmarks. Retrieved from https:// www.aer.gov.au/system/files/ACIL\%20Allen \%20Electricity\% 20Benchmarks final $\% 20$ report $\% 20 \mathrm{v} 2 \% 20$ - $\% 20$ Revised $\%$ 20March\%202015.PDF

3. Adil AM, Ko Y (2016) Socio-technical evolution of decentralized energy systems: a critical review and implications for urban planning and policy. Renewable and Sustainable Energy Reviews 57: 1025-1037. https://doi.org/10.1016/j.rser.2015.12.079

4. Akaike H (1974) A new look at the statistical model identification. IEEE Trans Autom Control 19(6):716-723

5. Alexander D., Wyndham J., James G., \& L., M. (2017). Networks renewed: technical analysis. Retrieved from Sydney, Australia: https://www.uts.edu.au/sites/default/files/ NetworksRenewedTechnicalAnalysis.pdf

6. APVI. (2017). Solar Pv Maps and Tools. Retrieved from http://pvmap.apvi.org.au/

7. ARENA. (2018). National map. Retrieved from http://nationalmap. gov.au/renewables/ retrieved on 21 June 2018

8. Australian_Electoral_Commission. (2018). Download Official Election Statistics. Retrieved from http://www.aec.gov.au/ Elections/Federal_Elections/Stats_CDRom.htm Retrieved on 02/ 02/2018

9. Bashiri A, Alizadeh SH (2018) The analysis of demographics, environmental and knowledge factors affecting prospective residential Pv system adoption: a study in Tehran. Renew Sust Energ Rev 81: 3131-3139

10. Boulaire F, Higgins A, Foliente G, McNamara C (2014) Statistical modelling of district-level residential electricity use in Nsw, Australia. Sustain Sci 9(1):77-88

11. Candas S, Siala K, Hamacher T (2019) Sociodynamic modeling of small-scale Pv adoption and insights on future expansion without feed-in tariffs. Energy Policy 125:521-536

12. Currie, G. (2017). Understanding Household Solar Adoption in Australia. Paper presented at the ZEMCH 2018 International conference, Melbourne, Australia
13. Currie G, Evans R, Duffield C, Mareels I (2019) Policy options to regulate $\mathrm{Pv}$ in low voltage grids-Australian case with international implications. Technology and Economics of Smart Grids and Sustainable Energy 4(1): 10

14. Eichler M (2012) Causal inference in time series analysis. Statistical perspectives and applications, Causality, pp 327-354

15. ESRI. (2016). Arcgis desktop: release 10.4.1: Environmental Systems Research Institute

16. Finkel, A. (2017). Electricity market review retrieved from http:// www.environment.gov.au/energy/publications/electricity-marketfinal-report. Retrieved 13/07/17

17. Ganu T, Seetharam DP, Arya V, Hazra J, Sinha D, Kunnath R, de Silva LC, Husain SA, Kalyanaraman S (2013) Nplug: an autonomous peak load controller. IEEE Journal on Selected Areas in Communications 31(7):1205-1218

18. Granger CW (1969) Investigating causal relations by econometric models and cross-spectral methods. Journal of the Econometric Society, Econometrica, pp 424-438

19. GreenSync. (2019). Vpp Project. Retrieved from https://greensync. com/solutions/greensync-vpp/ Retrieved on 1 January 2019

20. Higgins A, McNamara C, Foliente G (2014) Modelling future uptake of solar photo-Voltaics and water heaters under different government incentives. Technol Forecast Soc Chang 83:142-155

21. Hydro, S. (2018). Snowy 2.0. Retrieved from (https://www. snowyhydro.com.au/our-scheme/snowy20/about-snowy-2-0-2/) retrieved on 21 June 2018

22. IBM (2015) Ibm Spss statistics for windows, version 22.0. IBM Corp, Armonk, NY

23. Lee M, Hong T (2019) Hybrid agent-based modeling of rooftop solar photovoltaic adoption by integrating the geographic information system and data mining technique. Energy Convers Manag 183:266-279

24. Pink B (2011) Australian statistical geography standard (Asgs): volume 5-remoteness structure. Australian Bureau of Statistics, Canberra

25. Rai V, Henry AD (2016) Agent-based modelling of consumer energy choices. Nat Clim Chang 6(6):556-562

26. Reiter, E., Ardani, K., Margolis, R., \& Edge, R. (2015). Industry perspectives on advanced inverters for us solar photovoltaic systems. Grid Benefits, Deployment Challenges, and Emerging Solutions (NREL/TP-7A40-65063). Retrieved from Golden, CO (United States): https://www.nrel.gov/docs/fy15osti/65063.pdf

27. Reneweconomy. (2017). Agl Bought Liddell for Nothing, but What Will It Cost Turnbull. Retrieved from (https://reneweconomy.com. au/agl-bought-liddell-for-nothing-what-will-it-cost-turnbull14579/) Retrieved on 21 June 2018

28. Schiera DS, Minuto FD, Bottaccioli L, Borchiellini R, Lanzini A (2019) Analysis of rooftop photovoltaics diffusion in energy community buildings by a novel Gis-and agent-based modeling cosimulation platform. IEEE Access 7:93404-93432

29. Sommerfeld J, Buys L, Mengersen K, Vine D (2017) Influence of demographic variables on uptake of domestic solar photovoltaic technology. Renew Sust Energ Rev 67:315-323

30. Stern, D. I. (2011). From correlation to Granger causality. Crawford School Research Paper, From Correlation to Granger Causality

31. Toda HY, Yamamoto T (1995) Statistical inference in vector autoregressions with possibly integrated processes. J Econ 66(1): 225-250

32. Xia, L., Mareels, I., Alpcan, T., Brazil, M., Hoog, J. D \& Thomas, D. A. (2014). A Distributed Electric Vehicle Charging Management Algorithm Using Only Local Measurements. Paper presented at the ISGT 2014, Washington

Publisher's Note Springer Nature remains neutral with regard to jurisdictional claims in published maps and institutional affiliations. 